DOI: https://doi.org/10.21721/p2p.2018v5n1.p43-69

\title{
A INFLUÊNCIA DA INOVATIVIDADE E DO FINANCIAMENTO SOBRE O RESULTADO EM WEB STARTUPS BRASILEIRAS
}

\author{
Anselmo Luiz Éden Battisti \\ Universidade Federal Fluminense - UFF \\ anselmo@webgenium.com.br \\ Carlos Olavo Quandt \\ Pontifícia Universidade Católica do Paraná - PUC-PR \\ carlos.quandt@pucpr.br
}

\begin{abstract}
Resumo
A inovatividade e os resultados são cruciais para a sobrevivência das webs startups, empresas de base tecnológica. A obtenção de capital para o seu financiamento não é simples. Os mecanismos tradicionais de financiamento exigem garantias que raramente podem ser satisfeitas por estas organizações. Com isso, meios alternativos de financiamento surgiram para dar suporte as startups. Este trabalho visa investigar a relação existente entre a inovatividade, o financiamento e o resultado em startups. Esta pesquisa é correlacional-causal com corte transversal. A unidade de análise são startups brasileiras. Foi utilizado como instrumento de coleta de dados questionário estruturado. A análise dos dados foi quantitativa utilizando análise fatorial. Alguns resultados obtidos são que no Brasil as startups estruturam seu capital primeiramente pelo autofinanciamento, em seguida com os modelos alternativos e por fim utilizam o financiamento tradicionais, observou-se também que a inovatividade afeta positivamente a obtenção recursos que por sua vez influencia o resultado.
\end{abstract}

Palavras-chave: Inovatividade. Financiamento. Empreendedorismo. Startup.

\section{THE INFLUENCE OF INNOVATIVENESS AND FINANCING ON THE OUTCOME IN BRAZILIAN WEB STARTUPS}

\begin{abstract}
Innovativeness and results, are crucial to the survival of web startups, technology-based companies. Obtaining capital for it's financing is difficult. Traditional financing mechanisms require guarantees that can rarely be met by these organizations. Thus, alternative means of financing emerged to support startups. This work aims to investigate the relationship between innovation, financing and results in startups. This research is correlationalcausal with cross-section. The unit of analysis are Brazilian startups. Structured surveys was used as instrument of data collection. Data analysis was based on factorial analysis. Some results obtained are that in Brazil the startups structure their capital first by self-financing, then with the alternative models and finally they use the traditional financing, it was also observed that the innovativeness positively affects the obtaining resources that in turn influence the result.
\end{abstract}

Keywords: Innovativeness. Financing. Entrepreneurship. Startup. 


\section{INTRODUÇÃO}

A criação de tecnologias como: transistor; microprocessador e redes de computadores, transformou o modo como a sociedade se organiza (CASTELLS, 1997). A ordem social apresentada ao mundo após revolução industrial foi modificada. Esta nova sociedade onde a informação tem papel central, chamamos de sociedade da informação (PINHO, 2011).

$\mathrm{O}$ risco inerente à incerteza de novos negócios sempre existiu. O capital, motor propulsor do capitalismo, foi amplamente estudado e, modelos de risco foram desenvolvidos para minimizar perdas em ambientes incertos (SHARPE, 1964). Em geral o investidor possui pouco conhecimento sob o comportamento dos mercados emergentes.

A introdução constante de novas tecnologias aumenta as incertezas do mercado. As organizações necessitam desenvolver processos adaptativas para que possam se reinventar rapidamente frente estas inovações (CASTELLS, 1997). Esta flexibilidade procura reduzir os riscos gerados pela incerteza, e aumentar a capacidade produtiva.

Novos empreendimentos nos setores de tecnologia da informação (TI) possuem grande potencial econômico. As startups, como estes empreendimentos são chamados, são fomentadas por governos de diversos países (SCHUBERT; HAUSLER, 2001). Alguns dos motivos são: criam empregos com altos salário, geram receitas para o governo, possuem baixo risco ambiental. Mesmo atuando em um setor onde a informação e o conhecimento são altamente relevantes, o capital financeiro é necessário para a criação de uma startup.

Nas duas últimas décadas, o Brasil passou por modificações na forma como novos empreendedores iniciam suas atividades. Em pesquisa realizada por (VIEIRA, 2013), observouse que entre 2002 e 2013 aumentou a taxa do empreendedorismo por oportunidade, este valor passou de $42 \%$ para $71 \%$. Outras mudanças foram políticas públicas e instituições de apoio ao microempreendedor, como por exemplo: implantação do estatuto da micro e pequena empresa em 1984; implantação em 1996 do modelo simplificado de pagamento de impostos e a criação da lei geral da pequena empresa em 2006.

Empresas entrantes no mercado, segundo (STINCHCOMBE, 1965), apresentam maiores taxas de fechamento do que as já consolidadas. Este fenômeno é chamado "Passivo da Novidade". Ele afirma que estas empresas fecham, pois ainda lhes falta organização interna, e por possuírem laços frágeis com compradores e fornecedores.

Uma das formas de se construir laços externos é pela realização de alianças estratégias. Elas influenciam o desempenho de uma organização. Aspectos como controle e custos ajudam a explicar o sucesso ou o fracasso de uma aliança (GULATI, 1998; KLOTZLE, 2002). Uma 
aliança estratégica pode oferecer recursos, bem como, integrar capital intelectual ao novo negócio (BAUM; SILVERMAN, 2004). Em geral, busca-se o dinheiro-inteligente, aquele que além de financiar as operações também agrega conhecimento e amplia a rede de relacionamentos (SPINA, 2012; TIDD; BESSANT; PAVITT, 2008).

Dentro das diversas fontes de vantagem competitiva de uma organização, o conhecimento tácito é uma das mais duradouras. A formalização do conhecimento tácito em um conhecimento explícito, não é uma tarefa simples e, em alguns casos impossível (ICHIJO; NONAKA, 2007). Entretanto, este processo é importante para que a mesma crie ativos tangíveis. Um exemplo desta formalização do conhecimento ocorre quando patentes são geradas. Um dos fatores que influenciam o processo de obtenção de capital é a tangibilidade dos ativos de uma organização (CASSAR, 2014; CONTI; THURSBY; THURSBY, 2013).

A inovação constante é fundamental para que uma organização sobreviva. Porém, o seu início depende de algum tipo de financiamento. Desta forma, este trabalho procura analisar a inovatividade, o financiamento e a relação destas com o resultado em startups. O objetivo geral desta pesquisa é: "Verificar qual a relação entre inovatividade; recurso e o resultado nas startups". Para tanto, apresenta-se no Quadro 1 as hipóteses de pesquisa.

Quadro 1 - Hipóteses da pesquisa.

$$
\begin{aligned}
& \text { H01 - O tipo de financiamento não influencia o resultado; } \\
& \text { H02 - O recurso não influencia o resultado; } \\
& \text { H03 - A inovatividade não influencia o resultado; } \\
& \text { H04 - A inovatividade não influencia o recurso. }
\end{aligned}
$$

Fonte: Elaborado pelo autor.

O artigo está estruturado da seguinte forma. Inicia-se apresentando os conceitos sobre inovatividade e financiamento em startups, bem como o conceito de resultado em startups, em seguida será descrito o método utilizado na coleta e análise dos dados, logo após serão apresentados os resultados, bem como, algumas de suas implicações e, por fim as hipóteses de pesquisa serão detalhadas e amplamente discutidas nas considerações finais desta pesquisa.

\section{FUNDAMENTAÇÃO TEÓRICA EMPÍRICA}

\subsection{INOVATIVIDADE}

A inovação é o resultado da mobilização de um conjunto de recursos, comportamentos e atividades que possibilitam o desenvolvimento de novos produtos, processos e sistemas (QUANDT; FERRARESI; BEZERRA, 2013). Portanto, o seu surgimento está associado à convergência de vários fatores complexos e dinâmicos em um contexto organizacional 
específico. Sem inovação, a proposta de valor de uma organização pode eventualmente ser copiada pelos concorrentes, deixando a competição limitada ao aspecto preço (KAPLAN; NORTON, 2004b).

A inovatividade é a capacidade de inovar de forma contínua e duradoura (QUANDT; FERRARESI; BEZERRA, 2013). Em sua pesquisa (PORTER; KETELS, 2003) evidenciam que existe relação entre a rede de relacionamento organizacional com seus aspectos inovadores. Por outro lado, (QUANDT; FERRARESI; FREGA, 2012), encontraram relação positiva entre o desempenho inovador e aspectos como: aprendizagem, valorização do comportamento empreendedor, esforços para a interiorização do conhecimento. Desta forma, podemos entender que o fenômeno inovatividade pode ser influenciado tanto por fatores internos e externos a organização. Este trabalho adotará como instrumento para a análise da inovatividade organizacional o modelo proposto por (QUANDT; FERRARESI; BEZERRA, 2013), que foi construído e centralizado sobre três vertentes:

a) Há existência de condições organizacionais para explorar o conhecimento como um recurso estratégico;

b) Sua aplicação na obtenção de outros recursos necessários para a organização;

c) Desenvolvimento da capacidade contínua e duradoura para a geração de inovações em um ambiente competitivo e dinâmico.

A tentativa de relacionar a inovação aos resultados empresariais é alvo de diversas pesquisas. Para (BRITO; BRITO; MORGANTI, 2009), existem evidências empíricas que esta relação exista, porém, a operacionalização deste tipo de mensuração é fonte de debate devido aos diversos fatores que podem influenciar tanto a inovação como os resultados empresariais. A inovação também é associada frequentemente com os mecanismos de financiamento. Trabalhos realizados por Huergo; Moreno (2014) e Pinto (1996), apontam que diversos modelos alternativos de financiamento tem sido desenvolvido para fomentar inovações organizacionais. Com base no exposto, a inovação constante pode influenciar tanto o resultado organizacional como a obtenção de recursos para financiar atividades inovativas.

\subsection{STARTUPS}

O estudo das startups está relacionado com o empreendedorismo. Esse campo ainda possui objetos de interesse e domínios muito amplos (FERREIRA; PINTO; MIRANDA, 2015). Sendo assim, é natural que o conceito de startup ainda não possua uma definição clara. (BECKMAN; SINHA, 2009). 
Uma startup é uma organização criada para desenvolver novos produtos ou serviços sob condições de extrema incerteza (RIES, 2011), que está em desenvolvimento e evolui por cinco fases independentes, sendo elas: Cliente, Produto, Equipe, Modelo de Negócio e Financiamento (MARMER; HERRMANN; DOGRULTAN, 2012), o modelo de negócio deve possuir duas características: ser repetível e escalável (GRANDO, 2012), possuindo tempo de vida menor do que um ano e faturamento inferior a 360 mil reais ao ano, ou que ainda esteja em estágio de financiamento (ABES, 2013). As etapas podem ser definidas como:

a) Cliente: representa os consumidores em potencial do novo produto ou serviço;

b) Produtos: definições claras sobre quais, os principais produtos da startup;

c) Equipe: pessoas com capacidade técnica e operacional para transformar o projeto em produto;

d) Modelo de negócio: como será a captura de valor, sendo ele financeiro ou não;

e) Financiamento: como será o aporte de capital para fomentar o negócio.

f) Nas startups o modelo de negócio deve atender a dois pré-requisitos: ser escalável e repetível (DRAPER, 2012). Apesar deste conceito ser amplamente difundido, menos de 10\% das startups conseguem atingir o resultado almejado (MARMER; HERRMANN; DOGRULTAN, 2012). A seguir a definição dos conceitos de escalabilidade e repetibilidade:

g) Escalabilidade: é a relação existente entre os custos de manutenção da startup e os ganhos obtidos pela mesma. O crescimento do custo deve ser linear, ao passo que o crescimento da receita deve se comportar exponencial (RIES, 2011).

h) Repetibilidade: os produtos ou serviços oferecidos pelas startups devem ser padronizados para atender ao maior número de clientes, assim, os custos de personalizações serão baixos ou inexistentes (RIES, 2011).

\subsection{FINANCIAMENTO E RECURSOS EM STARTUPS}

Uma organização é formata pelos seus recursos tangíveis e intangíveis (KAPLAN; NORTON, 2004b). As startups demandam recursos destas duas naturezas. Neste trabalho foi considerado recurso tangível o capital financeiro vindo de financiamento, sendo ele externo ou interno. Como recurso intangível foi considerado tudo aquilo que advém de forma implícita ao financiamento, ou seja, o conhecimento agregado, influência e network gerado em função da entrada de um investidor na startup.

O financiamento de uma startup é realizado pelos investidores quando são atendidas as expectativas de retorno do capital investido em relação ao tempo do investimento, essa relação denomina-se "margem de atratividade" (ABREU et al., 2011). A margem de atratividade e os recursos mínimos necessários vão estabelecer os limites de financiamento que são necessários 
para a continuidade do projeto (CHESBROUGH; ROSENBLOOM, 2002). A viabilidade do projeto estará intimamente relacionada com a escalabilidade, a repetição do modelo de negócio e o tipo de financiamento disponível ao empreendedor.

Existem diversas formas de se financiar o início de uma startup. A fase embrionária de uma startup é conhecida como bootstrap. A forma dominante de financiamento externo em startups são as empresas de Capital de Risco (BAUM; SILVERMAN, 2004). No Quadro 2 são apresentadas alguns dos tipos de financiamento utilizado pelos empreendedores.

Quadro 2 - Tipos de financiamento em startups.

\begin{tabular}{|c|c|}
\hline Tipo & Definição \\
\hline Capital Próprio & O empreendedor investe o dinheiro acumulado ao longo de sua carreira. \\
\hline Amigos, Família & Pessoas próximas ao empreendedor investem seu capital no novo negócio. \\
\hline Empréstimo em Banco & $\begin{array}{l}\text { O empreendedor contrai junto a bancos financiamentos pessoais, geralmente } \\
\text { dando como garantia bens pessoais. }\end{array}$ \\
\hline Financiamento (Finep, etc.) & São tipos de financiamentos com algum benefício governamental. \\
\hline Incentivos & $\begin{array}{l}\text { São concursos onde diversas startups participam e a ganhadora recebe o } \\
\text { patrocínio, exemplos: Google Summer of Code, Prêmio FINEP, etc. }\end{array}$ \\
\hline Financiamento pelo Cliente & $\begin{array}{l}\text { Futuros clientes interessados no desenvolvimento da nova empresa, produto } \\
\text { ou serviço. Os clientes são outras empresas já constituídas. }\end{array}$ \\
\hline Crowdfunding & $\begin{array}{l}\text { Similar ao financiamento pelo cliente, porém o modo de arrecadação do } \\
\text { capital para o negócio se dá pelo uso de plataformas virtuais que mobilizam } \\
\text { pessoas físicas que tem interesse na nova empresa, produto ou serviço } \\
\text { oferecido. }\end{array}$ \\
\hline Emprego Alternativo & $\begin{array}{l}\text { Um dos fundadores da startup mantem o seu emprego com o objetivo de } \\
\text { financiar o desenvolvimento da mesma em sua fase inicial. }\end{array}$ \\
\hline
\end{tabular}

Fonte: Adaptado de (GRANDO, 2012).

Dentre as diversas teorias que explicam a estrutura de capital de uma organização, uma das mais populares é a Pecking Order Theory (POT). Nela o custo do financiamento se alinha proporcionalmente com a assimetria de informação entre investidor e empreendedor. Além disso, os empreendedores utilizam recursos próprios antes de buscar recursos externos, seja com empréstimos bancárias ou oferecendo direito para terceiros (MYERS; MAJLUF, 1984). O tipo de financiamento e sua ordem temporal na POT podem ser vista na Erro! Fonte de referência não encontrada. 
Figura 1 - - Escolha de financiamento pelos empresários segundo a POT.

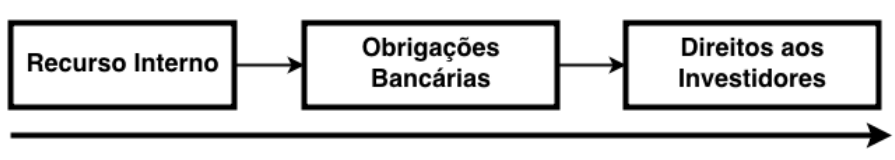

Tempo de Vida e Tamanho da Organização

Fonte: Elaborado pelo autor.

A validade da aplicação desta teoria em startups ainda é questão de debate. Estudos empíricos realizados por Fourati; Affes (2013) e Paul; Whittam; Wyper (2007), apontam que em startups os empreendedores optam pelo direito aos investidores em detrimento de obrigações bancárias. Essa situação pode ser explicada pela falta de oportunidades existentes de financiamento utilizando débitos bancários pelos empreendedores que atuam neste segmento da economia (VERHEUL; THURIK, 2001).

O tipo de financiamento varia de acordo com a fase da organização pois, ao longo do tempo as necessidades de capital modificam-se (GREGORY et al., 2005; PANIGRAHI, 2011; SPINA, 2012). Na 
Figura 1 podemos ver as etapas genéricas de financiamento, porém a ordem pode variar de acordo com a organização ou o mercado. O uso de capital próprio segundo (PEREIRA; GOMES, 2014), deve ser considerado financiamento pois impossibilita o uso do mesmo para outras oportunidades mercadológicas., ou seja, mesmo sendo capital próprio existe um custo associado pelo risco de uma possível oportunidade perdida.

Devido ao fato das startups serem suscetíveis a muitos riscos e, possuírem poucos dados tanto do próprio negócio como do mercado, existe uma incerteza considerável a respeito do real valor e dos possíveis resultados que a mesma pode gerar (BAUM; SILVERMAN, 2004). Este risco é potencializado devido a possibilidade do uso da nova tecnologia por empresas já consolidadas (ALDRICH; FIOL, 1994). Em web startups este risco é ainda maior, pois, a criação de um software que executa as mesmas rotinas de outro, em geral, não é uma tarefa muito difícil. A tecnologia por si só dificilmente trará vantagem competitiva sustentada (KAPLAN; NORTON, 2004a; TEECE; PISANO; SHUEN, 1997). 
Figura 1 - Tipos de investimento e sua a relação com a $P O T$.

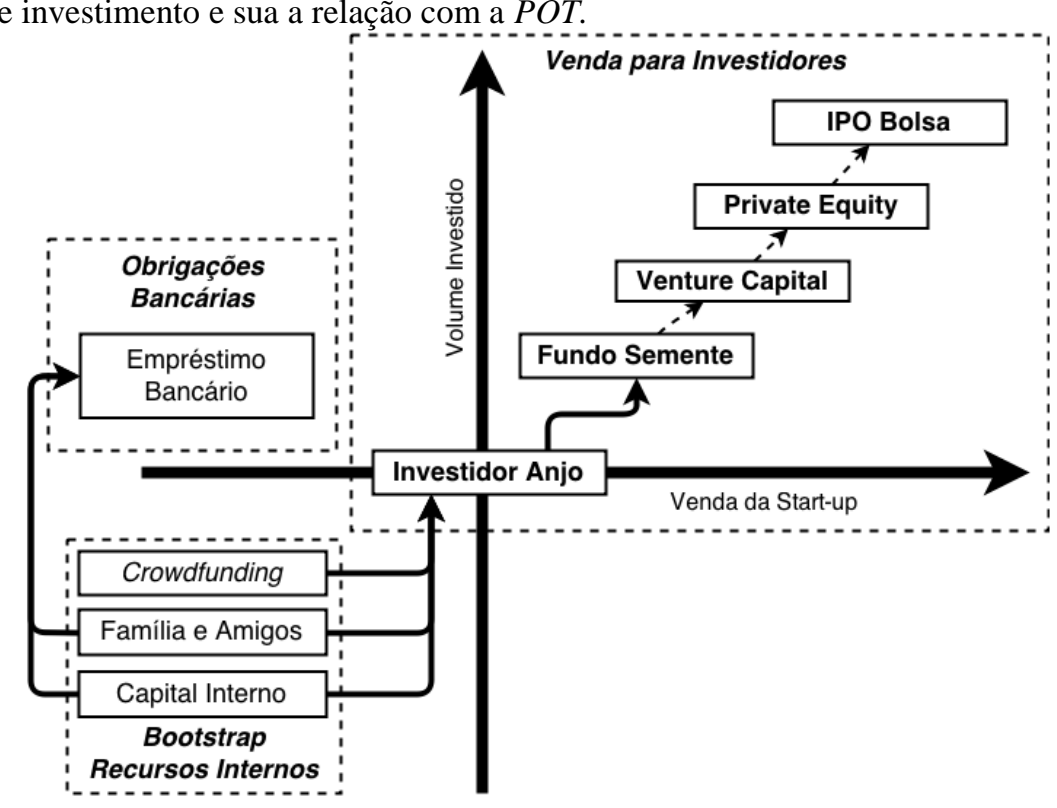

Fonte: Adaptado de (FOURATI; AFFES, 2013; GRANDO, 2012; SPINA, 2012).

As organizações evoluem por diversas razões. Segundo Aldrich (1999), quatro forças agem nessa evolução: variação; seleção; retenção e disputa. A seleção é interna ou externa, sendo o investidor um agente externo. O padrão adotado por eles sobre onde, quando e quanto investir é relevante pois influencia a forma como um mercado evolui.

\subsection{RESULTADOS EM STARTUPS}

No processo de monitoramento do desempenho organizacional, os indicadores são elementos críticos (CALDEIRA, 2012). A escolha deve englobar tanto os indicadores financeiros, contábeis e não contábeis. Ainda não existe um conjunto consagrado de indicadores de desempenho para o trabalho intelectual (DRUCKER, 1995), assim, indicadores de resultado consistentes para startups ainda não foram desenvolvidos, pois elas são organizações intensivas do trabalho intelectual.

A identificação do conjunto principal de indicadores de desempenho organizacional é uma tarefa bastante complexa. Em estudos realizados por Neely (1999), duas possibilidades para esta situação foram apresentadas. A primeira delas é que os indicadores que fazem sentido para a organização evoluem ao longo do tempo. A segunda é que nem sempre é óbvio identificar o que necessita ser mensurado. Desta forma, a construção destes indicadores deve passar por uma análise individual de cada setor da organização, além disso, eles devem ser constantemente revisados para verificar se ainda fazem sentido. 
A tangibilidade dos ativos de uma startup é pequena. Isso ocorre pois se tratam de empresas entrantes no mercado, cujo maior patrimônio são as ideias de novos produtos ou serviços inovadores. Diferentemente dos ativos financeiros e físicos, os ativos intangíveis são difíceis de serem medidos e copiados (KAPLAN; NORTON, 2004a).

Os ativos intangíveis vem ganhando relevância ao longo dos anos, Kaplan; Norton (2004b), apresentam que mais de $75 \%$ do valor agregado aos clientes é gerado pelos ativos intangíveis da organização. No mercado de ações este fenômeno se repete, grande parte do valor das ações de empresas small caps, empresas pequenas e com pouca liquidez, também derivam de seus ativos intangíveis (ROJO; SOUSA; TRENTO, 2012). Muitas vezes este tipo de ativo representa o conhecimento tácito de um grupo de colaboradores.

A taxa de retorno está diretamente relacionada com o risco envolvido ao investimento (LINTNER, 1965). Investidores que atuam em startup esperam taxas de retorno significativamente maiores do que as oferecidas por outros tipos de aplicações. Por exemplo, a taxa SELIC que é utilizada entre outras coisas para remunerar investidores de renda fixa teve média anual de $11 \%$ na última década, sendo assim, no Brasil, investimentos com rentabilidade esperada menor do que $12 \%$ tornam-se impraticáveis.

A relação entre o investimento em ativos intangíveis e o resultado é um importante elemento para sustentar a inovação. No Brasil, em pesquisa realizada por Miranda et al. (2013), foi observado uma relação positiva entre investimento em inovação e o valor de mercado da organização, porém, não houve relação direta entre o investimento em inovação e o resultado contábil. Isto mostra que investimentos em ativos intangíveis podem trazer resultados no longo prazo. Outro fator que pode gerar esta discrepância é a falta de definições claras sobre o que contabilizar como ativo intangível (PEREZ, 2006).

Diferentes startups podem utilizar diferentes modelos de negócio mesmo atuando no mesmo mercado. Este é um fator que pode dificultar o processo de determinação do seu resultado e valor de mercado. Outro aspecto importante é o tempo de vida relativamente curto da startup (AUDRETSCH; ACS, 1994). Resultados financeiros e contábeis são importantes como métricas de saúde organizacional. Investidores buscam minimizar os riscos utilizando instrumentos de controle e monitoramento. Indicadores de resultados não tangíveis devem ser inclusos nesta relação para a construção de um cenário mais realista da organização (KAPLAN; NORTON, 2004a).

Um dos instrumentos utilizados para a mensuração de resultados é o Balanced Scorecard (BSC). Ele não é prescritivo pois, deve ser adaptado em cada organização de acordo com a sua necessidade (COUTINHO; KALLÁS, 2005). O BSC está definido sobre quatro 
perspectivas: financeira; cliente; processo e aprendizagem. Neste trabalho, o construto resultado utilizará indicadores construídos sob a ótica do BSC.

$\mathrm{O}$ uso de indicadores financeiros e não financeiros é aceito para a mensuração de resultado pois, o contexto e a forma como os dados são analisados dão maior ou menor sentido aos dados. O modelo proposto por Sveiby (1997), apresenta um conjunto de indicadores para identificar os ativos intangíveis com a finalidade de mensurar o resultado organizacionais. O modelo prioriza três áreas: estrutura externa e interna, e competências (SVEIBY, 1997).

Ainda não existe um construto consagrado para a mensuração de resultados em startups, desta forma, este construto será elaborado em concordância com algumas observações identificadas durante a revisão da literatura. A operacionalização do construto resultado buscará a integração entre indicadores financeiros e não financeiros.

\section{PROCEDIMENTOS METODOLÓGICOS}

Segundo a taxonomia proposta por (SAMPIERI; COLLADO; LUCIO, 2013), este estudo pode ser caracterizado como sendo não experimental, transversal e correlacional-causal / descritivo. Esta classificação se justifica como não experimental pois, não foram controlados os valores das variáveis envolvidas no estudo. Ele é transversal com relação ao tempo haja visto que a pesquisa buscou retratar o fenômeno em um ponto temporal específico. O estudo é correlacional-causal pois procurou evidenciar a relação de causa e efeito entre os construtos e, descritivo pois apresentou a descrição de como um fenômeno ocorre.

A unidade de análise foram as startups. A população pode ser definida como as startups brasileiras do setor de TI, cujos produtos ou serviços sejam consumidos via Web. Foram admitidas startups que estivessem em qualquer nível de desenvolvimento.

A amostragem dos dados foi do tipo não probabilístico por conveniência. No Brasil não existe um repositório central de informações sobre este tipo de empresa. A base de dados adotada como referência para definição das startups que compuseram este estudo foi gerada a partir da união de diversas bases descentralizadas. As bases de dados utilizadas foram: dealbook, startupbase e startupi. Existem aproximadamente 3500 startups nestas três bases. Durante a seleção das startups na base de dados, observou-se que muitas não seguiam os critérios estabelecidos nesta pesquisa sobre as características básicas de uma startup. Os critérios adotados foram: $\mathrm{O}$ site da empresa deveria estar online; $\mathrm{O}$ site deveria possuir uma seção específica com descrições sobre os produtos ou serviços; os produtos ou serviços oferecidos deveriam ser inovadores e, o modelo de negócio deveria ser escalável e repetível. 
Ao final, foram selecionadas 651 empresas para a participação da pesquisa. Deste total, foi enviado para 613 empresas um e-mail explicativo com o link para o instrumento de pesquisa. Além disso, foi realizado contato telefônico com 260 destas empresas. A partir desta aplicação foram coletados 120 casos, destes 15 foram descartados devido ao preenchimento incorreto do formulário, desta forma 105 casos válidos foram utilizados nas posteriores análises realizadas nesta pesquisa.

A relação existente entre os construtos estudados pode ser vista na

- A hipótese H01 que relaciona o tipo do financiamento com o resultado foi analisada utilizando análise de cluster. As hipóteses H02, H03 e H04 foram estudadas utilizando equações estruturais. A variável Inovatividade é a variável independente deste estudo e as variáveis Resultado e Recurso são as variáveis dependentes.

Figura 3 - Esquema analítico dos construtos estudados.

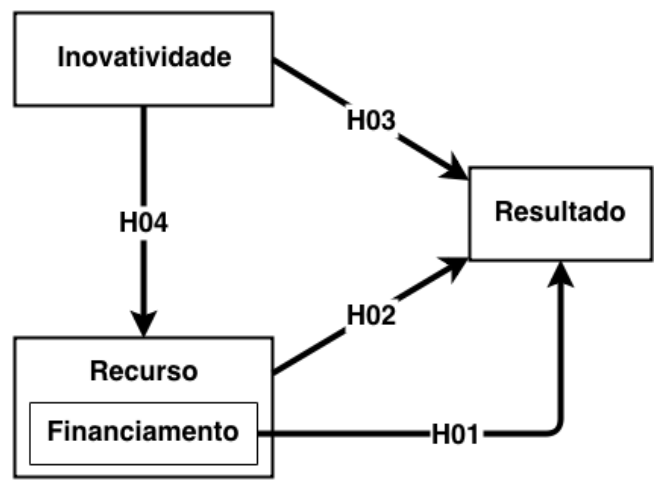

Fonte: Elaborado pelo autor.

A coleta dos dados foi realizada em uma única etapa. Os dados foram obtidos utilizando um formulário com assertivas objetivas em uma escala de 10 pontos. O instrumento foi construído de acordo com o modelo proposto por Quandt; Ferraresi e Bezerra (2013), que mede a inovatividade nas organizações. Neste formulário foram acrescentadas assertivas referentes ao resultado, financiamento e recursos das startups. Os respondentes desta pesquisa foram os gestores da organização (QUANDT; FERRARESI; BEZERRA, 2013).

\section{APRESENTAÇÃO E ANÁLISE DOS DADOS}

\subsection{PERFIS DAS STARTUPS RESPONDENTES}

Para facilitar o entendimento sobre as startups elas foram categorizadas quanto ao seu número de funcionários, Tabela 1. As categorias seguiram a distribuição de quartis. Outra categorização criada foi quanto a região onde a organização está localizada, Tabela 2. 
Tabela 1 - Agrupamento por número de funcionários.

\begin{tabular}{l|c|c|c}
\hline & Frequência & Porcentual & Porc. Acumulativa \\
\hline Abaixo de 4,5 & 26 & $24,8 \%$ & $24,8 \%$ \\
\hline 4,5 e 8 & 30 & $28,6 \%$ & $53,3 \%$ \\
\hline $8-12$ & 24 & $22,9 \%$ & $76,2 \%$ \\
\hline Acima de 12 & 25 & $23,8 \%$ & $100,0 \%$ \\
\hline Total & 105 & $100,0 \%$ & \\
\hline
\end{tabular}

Fonte: Dados da pesquisa, 2018.

O número médio de funcionários existentes nas startups brasileiras foi de 9,61. Além disso, observou-se um desvio padrão de 7,3 funcionários. Este dado mostra que existe uma grande discrepância entre o número de funcionários nas startups estudadas. A organização com o maior número de funcionários possui 40 colaboradores. Analisando a estatística moda sobre o número de funcionários, foi observado que a maioria das startups possui 6 colaboradores. Este valor representa $10,5 \%$ do número total de startups. A amplitude total referente ao número de funcionários foi de 39 , sendo que a empresa com o menor número de colabores era composta por apenas 1 integrante e, a empresa com maior número de colaboradores possuía 40 colaboradores.

Tabela 2 - Distribuição das startups por região.

\begin{tabular}{l|c|c|c}
\hline & Frequência & Porcentual & Porc. Acumulativa \\
\hline Centro-Oeste & 4 & $3,8 \%$ & $3,8 \%$ \\
\hline Nordeste & 7 & $6,7 \%$ & $10,5 \%$ \\
\hline Sudeste & 58 & $55,2 \%$ & $65,7 \%$ \\
\hline Sul & 36 & $34,3 \%$ & $100,0 \%$ \\
\hline Total & 105 & $100,0 \%$ & \\
\hline
\end{tabular}

Fonte: Dados da pesquisa, 2018.

Esta pesquisa teve abrangência nacional. Foi detectado grande concentração das startups nas regiões sul e sudeste do Brasil com $89 \%$. Não houveram casos de empresas respondentes na região Norte. A região Centro-Oeste e Nordeste juntas possuem $11 \%$. A distribuição por estado dentro das regiões analisadas foi praticamente homogênea.

\subsubsection{Perfil do Financiamento e Recursos}

Uma organização pode utilizar diversos tipos de financiamento. A distribuição das startups de acordo com o tipo de financiamento utilizado pode ser visto na

Tabela 3. Nesta tabela, uma mesma startup pode vigorar em mais de uma categoria, pois ela pode ter utilizado mais de um tipo de financiamento. Observa-se uma alta predominância do uso do capital próprio, além disso, os mecanismos tradicionais de financiamento foram pouco utilizados. 
Tabela 3 - Quantidade de empresas que utilizaram cada tipo de financiamento.

\begin{tabular}{l|c|c}
\hline Tipo de Financiamento & Número & Percentual \\
\hline Próprio & 93 & $88,57 \%$ \\
\hline Banco & 29 & $27,62 \%$ \\
\hline Alternativo & 48 & $45,71 \%$ \\
\hline
\end{tabular}

Fonte: Dados da pesquisa, 2018.

As startups também foram categorizadas quanto ao principal tipo de financiamento utilizado, Tabela 4. Cada startup foi computada uma única vez. O procedimento adotado para determinar em qual categoria a startup seria computada foi o maior valor indicado pelo respondente nas variáveis referente aos tipos de financiamento.

Pode-se observar na Tabela 4 que, $60 \%$ das startups utilizaram majoritariamente capital próprio, 21,90\% foram financiadas por mecanismos alternativos de crédito e, apenas 7,6\% utilizaram financiamento tradicionais como principal forma de financiamento.

Tabela 4 - Categorias para a estrutura de capital das startups.

\begin{tabular}{l|l|c|c|c}
\hline Variável & Tipo de Financiamento & Qtd & Percentual & Perc. Acumulado \\
\hline 11R3 & Próprio & 63 & $60,0 \%$ & $60,0 \%$ \\
\hline 11R4 & Banco & 8 & $7,60 \%$ & $67,6 \%$ \\
\hline $11 \mathrm{R} 5$ & Alternativo & 23 & $21,90 \%$ & $89,5 \%$ \\
\hline--- & Próprio-Banco & 7 & $6,70 \%$ & $96,2 \%$ \\
\hline--- & Próprio-Alternativo & 4 & $3,80 \%$ & $100,0 \%$ \\
\hline Total & 105 & $100 \%$ & \\
\hline
\end{tabular}

Fonte: Dados da pesquisa, 2018.

Com o objetivo de testar a hipótese "H01 - O tipo de financiamento não influencia no resultado" foi utilizado o Teste-T com amostras independentes. Este teste tem por objetivo verificar se existem diferenças significativas entre médias de grupos de variáveis. A Tabela 5 apresenta os resultados segmentados em dois grupos: empresas que utilizam financiamento próprio e aquelas empresas que não utilizam financiamento próprio.

Tabela 5 - Startup com financiamento próprio e externo em relação ao Resultado.

Fonte: Dados da pesquisa, 2018.

\begin{tabular}{l|c|c|c|c}
\hline & Número & Mediana & Média & D. Padrão \\
\hline Financiamento Próprio & 63 & 3 & $4,0397^{* * *}$ & 3,41374 \\
\hline Financiamento Externo & 42 & 6,75 & $6,5655^{* * *}$ & 2,77184 \\
\hline
\end{tabular}

$* * * \mathrm{p}<0,001$

O resultado obtido no teste de Levene foi sig $=0,00$. Assim, rejeita-se a hipótese de que as médias entre os dois grupos sejam iguais., portanto podemos concluir que existem evidências que apontam para uma distinção entre os resultados obtidos pela startup quando são utilizados recursos próprios e quando são utilizados recursos de fontes externas. Com base nos dados apresentados a hipótese H01 não foi verificada. 


\subsubsection{Inovatividade}

A inovatividade foi avaliada utilizando o instrumento de coleta de dados desenvolvido por Quandt; Ferraresi e Bezerra (2013). As assertivas estão divididas em 10 dimensões que representam fatores latentes de segunda ordem da inovatividade. Estas dimensões e suas métricas descritivas da inovatividade podem ser vistas na Tabela 6.

Tabela 6 - Medidas descritivas da inovatividade.

\begin{tabular}{l|l|l|l|l}
\hline Variável & Média & dPadrão & Assime & Curtose \\
\hline MED1 - Inovação & 6,77 & 2,13 & $-0,56$ & $-0,34$ \\
\hline MED2 - Estratégia & 7,26 & 2,36 & $\mathbf{- 0 , 9 5}$ & 0,07 \\
\hline MED3 - Cultura / Valores & $\mathbf{7 , 3 6}$ & 2,19 & $-0,90$ & $-0,01$ \\
\hline MED4 - Estrutura Organizacional & 6,32 & 2,67 & $-0,60$ & $-0,86$ \\
\hline MED5 - Processo & 5,50 & 2,45 & $-0,16$ & $-1,13$ \\
\hline MED6 - Pessoas & 5,77 & 2,63 & $-0,37$ & $-1,13$ \\
\hline $\begin{array}{l}\text { MED7 - Relacionamento / Networking / Aprendizado } \\
\text { com o ambiente }\end{array}$ & 6,13 & $\mathbf{2 , 7 3}$ & $-0,27$ & $-1,14$ \\
\hline MED8 - Infraestrutura / Tecnologia / Metodologias & 6,02 & 2,55 & $-0,41$ & $-0,84$ \\
\hline MED9 - Mensuração & $\mathbf{4 , 6 1}$ & 2,59 & 0,12 & $-1,23$ \\
\hline MED10 - Aprendizagem & 6,43 & 2,65 & $-0,53$ & $-0,95$ \\
\hline
\end{tabular}

Fonte: Dados da pesquisa.

Podemos observar que dentre as variáveis analisadas, aquela que apresentou a menor média foi “MED9 - Mensuração". A mensuração é um fator que preconiza o uso de indicadores para aperfeiçoar o processo de gestão da inovação (QUANDT; FERRARESI; BEZERRA, 2013), este processo é fundamental para a inovação constante. Como as startups são empresas em estágio inicial seus mecanismos de controle e de mensuração não estão completamente desenvolvidos, este fato pode explicar o valor baixo obtido nesta variável.

Outro fato digno de nota é que a variável "MED3 - Cultura / Valores", que mede a cultura organizacional obteve a maior média. A cultura influencia o compartilhamento do conhecimento; aprendizagem; autonomia (QUANDT; FERRARESI; BEZERRA, 2013). Além disso, a variável "MED2 - Estratégia" possui uma assimetria negativa de -0,95.

Analisando o desvio padrão das variáveis podemos observar que a "MED7 Relacionamento / Networking / Aprendizado com o ambiente" apresenta o maior valor entre todas as variáveis. Esta variável mede o relacionamento da organização com agentes externos e a aprendizagem com o ambiente, incluindo práticas de inteligência competitiva, criação de redes e acordos de cooperação (QUANDT; FERRARESI; BEZERRA, 2013; TIDD; BESSANT; PAVITT, 2008). Esta situação pode ser explicada devido a abrangência desta pesquisa, nas diversas regiões do país o ecossistema que suporta as startups oferece condições diferentes, o que poderia explicar esta discrepância. 
A inovatividade é a capacidade de inovar de forma contínua e duradoura (QUANDT; FERRARESI; BEZERRA, 2013). A média geral de todos os construtos que compõem a inovatividade foi de 6,21. O valor da inovatividade varia em uma escala de 1 até 10 , assim existe possibilidade de crescimento da inovatividade nas startups brasileiras.

Antes de prosseguir com as análises dos dados, foi realizada a mensuração do índice de confiabilidade interna dos construtos. A Tabela 7 apresenta os valores finais obtidos após a realização das devidas adequações do modelo.

Tabela 7 - Teste de confiabilidade interna dos construtos.

Fonte: Dados da pesquisa, 2018.

\begin{tabular}{l|c}
\hline Construto & Alfa de Cronbach \\
\hline Fator 1 - Inovatividade & 0,936 \\
\hline Fator 2 - Resultado & 0,950 \\
\hline Fator 3 - Recursos & 0,914 \\
\hline
\end{tabular}

\subsection{ANÁLISE FATORIAL EXPLORATÓRIA}

\subsubsection{Análise Fatorial Exploratória: Inovatividade}

A identificação dos fatores foi realizada pelo uso do método de análise de componentes principais, normalização KMO e, rotação pelo método Varimax. Pela análise de autovalores e pela observação do screen plot ficou comprovada a unidimencionalidade desta variável latente de primeira ordem. A variância total explicada por este construto foi de $68,37 \%$, como pode ser visto na Tabela 8.

O teste KMO, Kaiser-Meier-Olkin, cujo objetivo é medir a adequação da amostragem alcançou 0,921 , sendo assim, considerado excelente na respectiva escala de medição. O teste de esfericidade de Bartlett demonstrou que existe relação suficiente entre os indicadores para a aplicação da análise fatorial $(\operatorname{sig}<0,05)$.

Tabela 8 - Matriz de componentes dimensão Inovatividade.

\begin{tabular}{l|c}
\hline Total da Variância Explicada $=68,37 \%$ & Componente \\
\hline MED1 - Inovação & 0,71 \\
\hline MED2 - Estratégia & 0,726 \\
\hline MED3 - Cultura / Valores & 0,755 \\
\hline MED4 - Estrutura Organizacional & 0,795 \\
\hline MED5 - Processo & 0,865 \\
\hline MED6 - Pessoas & 0,858 \\
\hline MED7 - Relacionamento / Networking / Aprendizado com o ambiente & 0,809 \\
\hline MED8 - Infraestrutura / Tecnologia / Metodologias & 0,845 \\
\hline MED9 - Mensuração & 0,787 \\
\hline MED10 - Aprendizagem & 0,901 \\
\hline
\end{tabular}

Fonte: Dados da pesquisa, 2018. 


\subsubsection{Análise Fatorial Exploratória: Recurso}

A identificação dos fatores foi realizada pelo uso do método de análise de componentes principais, normalização KMO e, rotação pelo método Varimax. Pela análise de autovalores e pela observação do screen plot ficou comprovada a unidimencionalidade desta variável latente de primeira ordem. A variância total explicada por este construto foi de 80,02\%, como pode ser visto no Tabela 9.

O teste KMO, Kaiser-Meier-Olkin alcançou 0,763, sendo assim considerado bom, na respectiva escala de medição. O teste de esfericidade de Bartlett demonstrou que existe relação suficiente entre os indicadores para a aplicação da análise fatorial (sig < 0,05).

Tabela 9 - Matriz de componentes dimensão Recurso.

\begin{tabular}{l|l}
\hline Total da Variância Explicada $=80,02 \%$ & Componente \\
\hline P11R2 -As suas necessidades inicias de financiamento externo foram atendidas de forma satisfatória. & 0,854 \\
\hline P11R6 -Surgiram novas oportunidades de negócios ou parcerias após o financiamento da startup. & 0,940 \\
\hline P11R7 -A experiência possuída pelos financiadores trouxe vantagens significativas ao negócio. & 0,949 \\
\hline P11R8 -A mídia gerada em função da obtenção do financiamento foi importante para a startup. & 0,807 \\
\hline
\end{tabular}

Fonte: Dados da pesquisa, 2018.

\subsubsection{Análise Fatorial Exploratória: Resultado}

A identificação dos fatores foi realizada pelo uso do método de análise de componentes principais, normalização KMO e, rotação pelo método Varimax. Pela análise autovalores e pela observação do screen plot ficou comprovada a unidimencionalidade desta variável latente de primeira ordem. A variância total explicada por este construto foi de $88,86 \%$, como pode ser visto na

Tabela 10.

O teste KMO, Kaiser-Meier-Olkin alcançou 0,852, sendo assim considerado muito bom, na respectiva escala de medição. O teste de esfericidade de Bartlett demonstrou que existe relação suficiente entre os indicadores para a aplicação da análise fatorial (sig < 0,05).

Tabela 10 - Matriz de componentes dimensão Resultado.

\begin{tabular}{l|l}
\hline Total da Variância Explicada $=88,86 \%$ & Componente \\
\hline P12R1 -Houve aumento no número de clientes (pagantes ou não pagantes) após o financiamento & 0,944 \\
\hline P12R2 -O valor financeiro gerado pelos clientes cresceu após o financiamento & 0,958 \\
\hline P12R3 -O número de novas funcionalidades implementadas aumentou após o financiamento & 0,922 \\
\hline P12R4 -Houve aumento no número de feedback positivos ou negativos após o financiamento & 0,903 \\
\hline
\end{tabular}

Fonte: Dados da pesquisa, 2018.

Após os devidos ajustes no modelo o mesmo foi submetido a análise fatorial exploratória. Este teste avalia a consistência do modelo. A extração dos fatores existentes na amostra condiz com o modelo teórico proposto, como pode ser visto na Tabela 11. A suposição 
inicial sobre o número de fatores existentes estava correta e, três fatores foram extraídos a partir dos dados da amostra. O Fator 1 foi identificado como sendo a Inovatividade, o Fator 2 o Resultado, e o Fator 3 são os Recursos.

Tabela 11 - Análise fatorial exploratória, extração de componentes.

\begin{tabular}{l|l|l|l}
\hline & Fator 1-Inovatividade & Fator 2-Resultado & Fator 3-Recurso \\
\hline P11R2 & & &, 779 \\
\hline P11R6 & & &, 841 \\
\hline P11R7 & & &, 896 \\
\hline P11R8 & &, 825 &, 711 \\
\hline P12R1 & &, 853 & \\
\hline P12R2 & &, 847 & \\
\hline P12R3 & &, 803 & \\
\hline P12R4 & & & \\
\hline MED1 &, 683 & & \\
\hline MED2 &, 698 & & \\
\hline MED3 &, 694 & & \\
\hline MED4 &, 757 & & \\
\hline MED5 &, 843 & & \\
\hline MED6 &, 819 & & \\
\hline MED7 &, 771 & & \\
\hline MED8 &, 830 & & \\
\hline MED9 &, 764 & & \\
\hline MED10 &, 856 & & \\
\hline
\end{tabular}

Fonte: Dados da pesquisa, 2018.

\subsection{ANÁLISE DO MODELO INTEGRADO E TESTES DE HIPÓTESE}

Durante a análise fatorial exploratória foi identificado que os construtos Resultado e Recurso possuíam apenas quatro variáveis, além disso, eles eram de primeira ordem. $\mathrm{O}$ construto Inovatividade que originalmente possuía subfatores foi convertido para que também se torna um construto de primeira ordem. Por esta razão, foi decidido realizar a análise fatorial confirmatória apenas do modelo integrado, o resultado final pode ser visto na Figura 2.

A análise fatorial confirmatória do modelo integrado inicial apresentou índices insatisfatórios. Desta forma, o modelo foi reespecificado utilizando a análise das estimativas transgressoras e dos Índices de Modificação (M.I) fornecidos pelo software AMOS ${ }^{\circledR}$.

Após constatação do baixo ajustamento do modelo, passou-se então a análise das médias obtidas por cada varáveis a fim de identificar alguma discrepância que pudesse causar este processo. O processo de reespecificação do modelo exigiu a exclusão da variável "P11R8 - A mídia gerada em função da obtenção do financiamento foi importante para a startup.”. Esta variável durante a análise descritiva dos dados teve destaque pois possuía a menor média dentre todas as variáveis observadas de todos os construtos. 
O ajuste do modelo apresentou-se em $\chi^{2}=185,604$ para 116 graus de liberdade. Este teste busca determinar o ajuste do modelo e dos dados observados. Apesar do seu valor ter sido relativamente alto, tendo em vista que o número de casos da amostra foi de 105 , temos um $\chi^{2 / g l}$ $=1,600$, valor muito abaixo do limite máximo preconizado pela literatura que é de 5 . Isto indica que o modelo possui uma boa qualidade. Além disso, o teste de bootstrap Bollen-Stine gerou um $\mathrm{p}=0,214$, impedindo assim a rejeição a 0,05 de significância da hipótese de que o modelo não seja representativo aos dados. O RMSEA $=0,076$ atingiu um valor maior do que o referenciado pela literatura que é de 0,05 , porém este valor ainda está dento dos limites toleráveis que vão até 0,08 (HAIR et al., 2009). O PCLOSE = 0,21 também indica bom ajustamento do modelo. $\mathrm{O} R \mathrm{RMR}=0,360$ foi considerado satisfatório.

Figura 2 - Modelo integrado final.

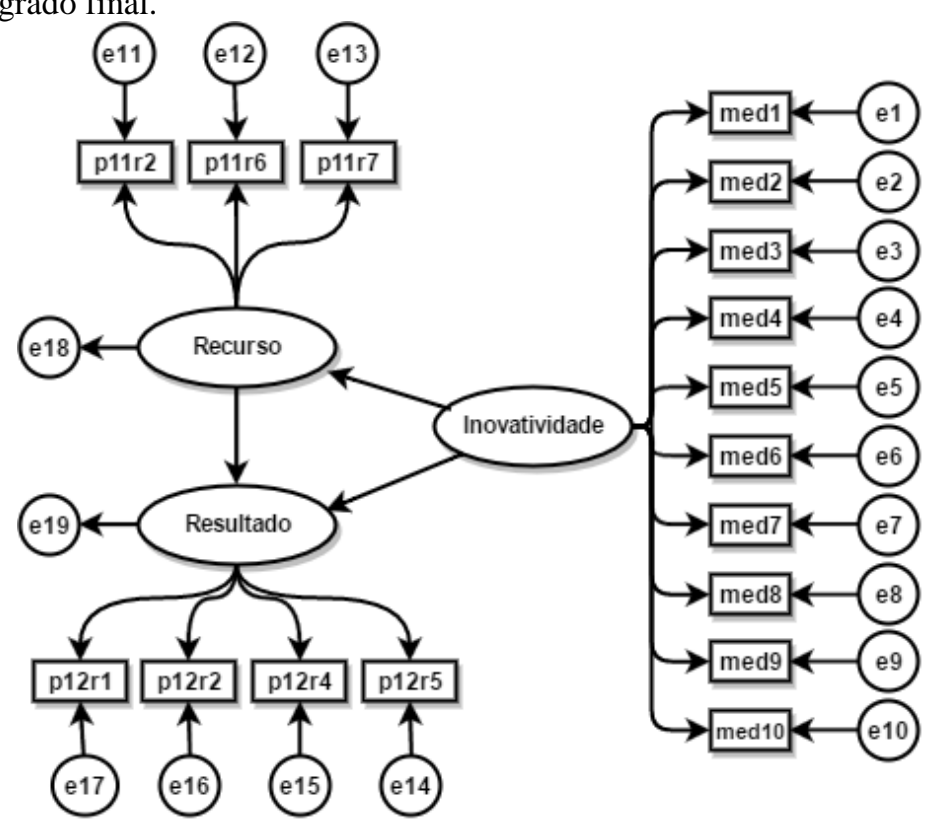

Fonte: Elaborado pelo autor.

\section{A}

Dada a exposição e análise dos diversos indicadores, entendeu-se que o modelo estava adequado aos propósitos dessa pesquisa. Foram analisados os demais dados resultantes da análise fatorial confirmatória para os testes de hipóteses. Os valores e as significâncias estatísticas dos coeficientes de regressão padronizados foram utilizados para os testes das hipóteses. Um resumo desses valores pode ser observado na Tabela 13. 
Tabela 12 apresenta a carga das variáveis de primeira ordem dos constructos. Pode-se observar que a variância extraída e a confiabilidade composta ficaram dentro dos parâmetros preconizados pela literatura. A variância extraída do Fator 1 - Inovatividade ficou próximo ao limite mínimo de 0,5 , porém com boa folga.

Dada a exposição e análise dos diversos indicadores, entendeu-se que o modelo estava adequado aos propósitos dessa pesquisa. Foram analisados os demais dados resultantes da análise fatorial confirmatória para os testes de hipóteses. Os valores e as significâncias estatísticas dos coeficientes de regressão padronizados foram utilizados para os testes das hipóteses. Um resumo desses valores pode ser observado na Tabela 13.

Tabela 12 - Cargas fatoriais das variáveis do modelo.

\begin{tabular}{l|l|l|l}
\hline & Fator 1-Inovatividade & $\begin{array}{l}\text { Fator } \\
\text { Resultado }\end{array}$ & Fator 3-Recurso \\
\hline MED1 & 0,719 & & \\
\hline MED2 & 0,711 & & \\
\hline MED3 & 0,772 & & \\
\hline MED4 & 0,789 & & \\
\hline MED5 & 0,825 & & \\
\hline MED6 & 0,828 & & \\
\hline MED7 & 0,788 & & \\
\hline MED8 & 0,781 & & \\
\hline MED9 & 0,763 & & 0,758 \\
\hline P11R2 & 0,897 & & 0,987 \\
\hline P11R6 & & & 0,924 \\
\hline P11R7 & & & \\
\hline P12R1 & & & \\
\hline P12R2 & & 0,758 & \\
\hline P12R3 & & 0,986 & 0,9226 \\
\hline P12R4 & & 0,924 & 0,8008 \\
\hline AVE & 0,9398 & 0,562 & \\
\hline
\end{tabular}

Fonte: Dados da pesquisa, 2018.

A hipótese "H02 - O recurso obtido não influencia no resultado" foi rejeitada a p $<0,05$, ou seja, existe influência entre os construtos Recurso e o Resultado. Desta forma, podemos corroborar a teoria proposta pela VBR de que os recursos de uma organização podem promovem resultados (BARNEY, 1991; BARNEY; WRIGHT; KETCHEN, 2001; TEECE; PISANO; SHUEN, 1997).

A hipótese "H02 - O recurso obtido não influencia no resultado" foi rejeitada a $p<0,05$, existe influência entre os construtos Recurso e o Resultado. Desta forma, podemos corroborar 
a teoria proposta pela VBR de que os recursos podem promovem resultados (BARNEY; WRIGHT; KETCHEN, 2001; TEECE; PISANO; SHUEN, 1997).

Tabela 13 - Resultado dos testes de hipóteses.

\begin{tabular}{l|l|l|l|l|l}
\hline H & \multicolumn{2}{|l|}{ Relação Estrutural } & Coeficiente & Situação \\
\hline H02 & Recurso & $\Rightarrow$ & Resultado & $0,593^{*}$ & Não Verificada \\
\hline H03 & Inovatividade & $\Rightarrow$ & Resultado & $0,260^{*}$ & Não Verificada \\
\hline H04 & Inovatividade & $=>$ & Recurso & $0,450^{*}$ & Não Verificada \\
\hline
\end{tabular}

Fonte: Dados da pesquisa, 2018.

* Resultados significativos a p<0,05 Não Verificada = Rejeição da Hipótese Nula

A hipótese "H03 - A inovatividade não influencia nos resultados" foi rejeitada a $\mathrm{p}<$ 0,05. Desta forma, podemos inferir que existe certa influência da Inovatividade sobre os Resultados nas startup. É importante observar que esta relação foi pequena e, seu poder de explicação $\mathrm{R}^{2}$ também foi baixo, como pode ser visto na Figura 3. Esta descoberta corrobora com os resultados obtidos em outras pesquisas realizadas que apontam pouca ou nenhuma relação direta entre a Inovação e os Resultados obtidos por uma organização. (ANDREASSI; SBRAGIA, 2002; BRITO; BRITO; MORGANTI, 2009; CHO; PUCIK, 2005).

A hipótese "H04 - A inovatividade não influencia a obtenção de recursos" foi rejeitada a $\mathrm{p}<0,05$. Desta forma, podemos inferir que existe influência da Inovatividade sobre os Recursos disponíveis por parte da startup. Nesta relação o poder de explicação $\mathrm{R}^{2}$ mostrou-se significativo como pode ser visto na Figura 3. De maneira geral as pesquisas realizadas apontam que a obtenção de recursos para inovação tende a esbarrar nas barreiras impostas pelo mercado de capital tradicional (CORDER; SALLES-FILHO, 2006; PINTO, 1996). Desta forma, podemos relacionar este resultado ao fato de que em geral, nas startups analisadas foram utilizados métodos alternativos de financiamento.

A Tabela 14 apresenta que o modelo estrutural proposto explica 55\% da variância observada no construto Recurso e, $20 \%$ da variância explicada no construto Resultado. Para melhorar o entendimento sobre o modelo também foram analisados os efeitos diretos, indiretos e totais entre os construtos do modelo. Essa relação pode ser vista na Tabela 14.

Figura 3 - Coeficientes e variância observada no modelo.

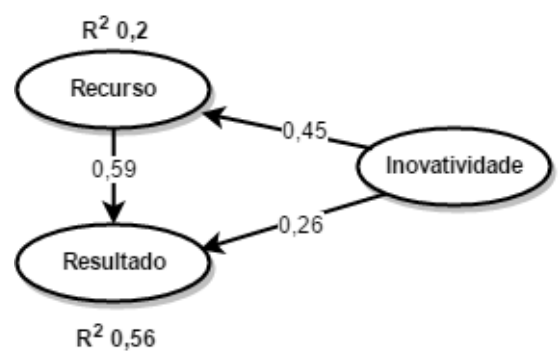

Fonte: Elaborado pelo autor, 2018. 
As relações observadas entre os construtos se mostraram condizentes com o modelo teórico proposto. A exceção foi a relação entre Inovatividade e Resultado. Nela, os efeitos indiretos são maiores do que os efeitos diretos. Isso pode ocorres pois a inovatividade é uma característica que gera influência em diversas áreas de uma organização. Essa descoberta corrobora as afirmações sobre as relações indiretas existentes entre inovação e resultados apresentado por (BRITO; BRITO; MORGANTI, 2009).

Tabela 14 - Efeitos diretos, indiretos e totais entre os construtos.

\begin{tabular}{l|l|l|l|l|l}
\hline Relação Estrutural & Efeitos Diretos & Efeitos Indiretos & Efeitos Totais \\
\hline Recurso & $\Rightarrow>$ & Resultado & 0,593 & --- & 0,593 \\
\hline Inovatividade & $\Rightarrow$ & Resultado & 0,260 & 0,267 & 0,527 \\
\hline Inovatividade & $\Rightarrow>$ & Recurso & 0,450 & --- & 0,450 \\
\hline
\end{tabular}

Fonte: Dados da pesquisa, 2018.

\section{CONSIDERAÇÕES FINAIS}

Foram coletados dados de 105 startups de todo o Brasil. O perfil das respondentes mostrou que elas são pequenas empresas, onde $80 \%$ possuem menos de 13 colaboradores. A empresa com o maior número de colaboradores foi 40 e a empresa com o menor número de colaboradores foi apenas 1. A organização com o maior número de colaboradores atua no setor de prestação de serviços. Seu principal produto é a criação de conteúdo personalizados para blogs e site corporativos. Desta forma, o número elevado de colaboradores justifica-se pois neste caso esta startup não satisfaz o requisito da escalabilidade.

A distribuição geográfica das startups também foi alvo de investigação desta pesquisa. As regiões Sul e Sudeste concentram mais de $80 \%$ das startups pesquisadas. A região Norte não teve nenhum caso analisado, empresas desta região foram inclusas no universo a ser pesquisado, porém, não houve sucesso na obtenção destes dados.

O objetivo principal das startups é gerar produtos e serviços inovadores. Neste tipo de empresa a flexibilização do modelo de trabalho é encorajado a fim de promover dentre os colaboradores formas de potencializar seus talentos. O alto valor obtido pela variável "MED3 - Cultura / Valores" explica este comportamento organizacional. As startups brasileiras tendem a encorajar seus colaboradores e buscam com isso o surgimento de uma forte cultura organizacional cujo propósito é promover a inovação.

A estrutura de capital existente nas startups difere tanto do modelo teórico oferecido pela POT quanto do padrão encontrado em pesquisas realizadas com startups americanas por (FOURATI; AFFES, 2013). No Brasil é utilizado capital próprio, em seguida capital advindo 
de financiamentos alternativos e por fim são utilizados recursos de bancos privados. Este achado foi embasado na distribuição das preferências do uso dos tipos de financiamentos nas startups. Foi detectado que 63,2 utilizam recursos próprios, 25,3\% recorrem aos mecanismos de financiamento alternativo e, apenas $11,5 \%$ optam pelo financiamento bancário tradicional.

O tipo de financiamento menos utilizado pelas startups foi o empréstimo bancário. Esse fenômeno pode ser explicado pelo fato destas instituições financeiras exigirem garantias reais. No caso das startups seu principal ativo é intangível, o conhecimento. Conhecimento pode ser convertido em moeda circulante pelo financiador no caso de não pagamento do capital tomado, portando a liberação de crédito bancário para startups é incomum.

Os modelos alternativos de financiamento ainda não estão totalmente disseminados dentro do mercado de investimento brasileiro. Mesmo o mercado tradicional de investimento, como a bolsa de valores ou ainda compra de títulos da dívida pública por pessoas físicas são fenômenos recentes no Brasil. O investimento do tipo anjo ainda precisa ser regulamentado. Esta regulamentação irá garantir o não comprometimento do patrimônio pessoal do investidor njo em caso de falência ou da existência de dívidas trabalhistas da startup financiada.

A hipótese nula "H01 - O tipo de financiamento não influencia no resultado" foi rejeitada, desta forma, podemos inferir que o tipo do financiamento utilizado pelas startups gera influência sobre os resultados obtidos pela mesma. Em geral observou-se melhores resultados nas startups que utilizavam majoritariamente financiamento externo para a construção da sua estrutura de capital. Esta característica pode ser causada devido a reflexos das dificuldades da própria obtenção de capital externo para este tipo de organização. Como o risco inerente a este tipo de negócio é relativamente alto, os investidores apenas aportam capital em organizações cujas chances da obtenção de bons resultados sejam elevadas.

A hipótese nula "H02 - O recurso obtido não influencia no resultado" foi rejeitada. Isto indicou que os Recursos obtidos por uma startup exercem influência sobre os Resultados da mesma, como proposto pela VBR.

A hipótese nula "H03 - A inovatividade não influencia o resultado" tinha como pressuposto a não existência de relação entre a Inovatividade e o Resultado. Esta hipótese não foi confirmada, sendo assim, é admissível a existência de relação entre estes dois construtos.

A hipótese nula "H04 - A inovatividade não influencia a obtenção de recursos", tinha como pressuposto a não existência de relação entre a Inovatividade e o Recurso. Esta hipótese não foi confirmada, logo, admissível a existência de relação entre estes dois construtos.

$\mathrm{O}$ tema estudado nesta pesquisa é um fenômeno relativamente novo. $\mathrm{O}$ marco teórico e empírico deste campo de estudo ainda está sendo estabelecido. Entretanto é inegável sua 
relevância tendo em vista a configuração social existente onde a TIC exerce grande influência sobre o nosso modo de vida.

As relações entre os construtos Inovatividade, Recurso e Resultado mostraram-se significativas. Os índices encontrados durante esta pesquisa oferecem evidências de que a Inovatividade influencia tanto os Resultados como os Recursos e que os Recursos por sua vez influenciam o Resultado. Desta forma, a busca pela Inovatividade e Recursos dentro das startups deve ser uma constante a fim de melhorar seus indicadores de desempenho.

Como principais limitações desta pesquisa temos que, ao final dos testes foi observado que alguns índices tomados como adequados durante a etapa de análise dos dados estavam muito próximo aos limites máximos ou mínimos aceitáveis. Além disso, a escolha dos casos deu-se de forma não probabilística.

Outra observação importante diz respeito à seleção dos casos desta pesquisa. No Brasil ainda não existe um repositório contendo todas as startups. Desta forma, os dados foram compilados de bases de dados desconexas. Tomando como premissa que podem existir startups representativas que não foram inclusas no rol de possíveis casos, pode-se inferir que existam discrepância entre os resultados aqui obtidos e o mundo real. 


\section{REFERENCIAS}

ABREU, J. C. F. et al. Finanças Corporativas. 10. ed. Rio de Janeiro: FGV Editora, 2011.

ALDRICH, H. Organizations evolving. London, UK: Sage, 1999.

ALDRICH, H. E.; FIOL, C. M. Fools Rush in? the Institutional Context of Industry Creation. Academy of Management Review, v. 19, n. 4, p. 645-670, 1 out. 1994.

ANDREASSI, T.; SBRAGIA, R. Relações entre indicadores de P \& D e de resultado empresarial. Revista de Administração, v. 37, n. 1, p. 72-84, 2002.

ASSOCIAÇÃO BRASILEIRA DAS EMPRESAS DE SOFTWARE (ABES). Mercado brasileiro de software, panorama e tendencias 2013. São Paulo: ABES, 2013.

AUDRETSCH, D.; ACS, Z. New-firm startups, technology, and macroeconomic fluctuations. Small Business Economics, p. 439-449, 1994.

BARNEY, J. B. Firm Resources and Sustained Competitive Advantage. Journal of Management, v. 17, n. 1, p. 99-120, 1991.

BARNEY, J.; WRIGHT, M.; KETCHEN, D. J. The resource-based view of the firm : Ten years after 1991. Journal of Management, v. 27, p. 625-641, 2001.

BAUM, J. A. C.; SILVERMAN, B. S. Picking winners or building them? Alliance, intellectual, and human capital as selection criteria in venture financing and performance of biotechnology startups. Journal of Business Venturing, v. 19, n. 3, p. 411-436, maio 2004.

BECKMAN, S.; SINHA, K. K. Conducting Academic Research with an Industry Focus: Production and Operations Management in the High Tech Industry. Production and Operations Management, v. 14, n. 2, p. 115-124, 5 jan. 2009.

BRITO, E. P. Z.; BRITO, L. A. L.; MORGANTI, F. Inovação e o desempenho empresarial: lucro ou crescimento? Revista de Administração de Empresas, v. 8, n. 1, 2009.

CALDEIRA, J. 100 indicadores da gestão key performance indicators. 1. ed. Lisboa: Actual, 2012.

CASSAR, G. Industry and startup experience on entrepreneur forecast performance in new firms. Journal of Business Venturing, v. 29, n. 1, p. 137-151, jan. 2014.

CASTELLS, M. The Rise of the Network Society. Cambridge, MA: Wiley-Blackwell, 1997. The Information Age: economy, society and culture, v. I.

CHESBROUGH, H.; ROSENBLOOM, R. S. The role of the business model in capturing value from innovation : evidence from Xerox Corporation's technology spin-off companies. Industrial and Corporate Change, v. 11, n. 3, p. 529-555, 2002.

CHO, H. J.; PUCIK, V. Relationship between innovativeness, quality, growth, profitability, and market value. Strategic Management Journal, v. 26, n. 6, p. 555-575, jun. 2005. 
CONTI, A.; THURSBY, J.; THURSBY, M. Patents as Signals for Startup Financing. The Journal of Industrial Economics, v. LXI, n. 3, p. 592-622, 2013.

CORDER, S.; SALLES-FILHO, S. Aspectos Conceituais do Financiamento à Inovação *. Revista Brasileira de Inovação, v. 5, n. 1, p. 33-76, 2006.

COUTINHO, A. R.; KALLÁS, D. (Org.). Gestão da estratégia: experiências e lições de empresas brasileiras. 1. ed. Rio de Janeiro: Elsevier, Reed, 2005.

DRAPER, W. H. O Jogo das Startups. 1. ed. Rio de Janeiro: Campus, 2012.

DRUCKER, P. The information executives truly need. Harvard Business Review, v. 73, n. 1, p. 54-62, 1995.

FERREIRA, M. P. V.; PINTO, C. F.; MIRANDA, R. M. Três Décadas De Pesquisa Em Empreendedorismo: Uma Revisão Dos Principais Periódicos Internacionais De Empreendedorismo. REAd. Revista Eletrônica de Administração, v. 21, n. 2, p. 406-436, 2015.

FOURATI, H.; AFFES, H. The Capital Structure of Business Start-Up: is there a pecking order theory or a reversed pecking order? Technology and Investment, v. 4, n. 4, p. 244-254, 2013.

GRANDO, N. Empreendedorismo inovador: como criar start-ups de tecnologia no Brasil. 1. ed. São Paulo: Ed. Evora, 2012.

GREGORY, B. T. et al. An Empirical Investigation of the Growth Cycle Theory of Small Firm Financing. Journal of Small Business Management, v. 43, n. 4, p. 382-392, out. 2005.

GULATI, R. Alliances and networks. Strategic management journal, v. 317, p. 293-317, 1998.

HAIR, J. F. et al. Análise Multivariada de Dados. 6. ed. Porto Alegre: Bookman, 2009.

HUERGO, E.; MORENO, L. National or international public funding? Subsidies or loans? Evaluating the innovation impact of $R \& D$ support programmesScience. Madrid: [s.n.]. Disponível em: 〈http://mpra.ub.uni-muenchen.de/54218/>. Acesso em: 15 maio 2018.

ICHIJO, K.; NONAKA, I. Knowledge Creation and Management: new challenges for managers. 1. ed. New York: Oxford University Press, 2007. v. 2011

KAPLAN, R.; NORTON, D. Measuring the strategic readiness of intangible assets. Harvard Business Review, v. 82, n. 2, p. 52-63., 2004a.

KAPLAN, R. S.; NORTON, D. P. Strategy Maps: converting intangible assets into tangible outcomes. Boston, MA: Harvard Business Press, 2004b.

KLOTZLE, M. C. Alianças estratégicas: conceito e teoria. Revista de Administração Contemporânea, v. 6, n. 1, p. 85-104, abr. 2002. 
LINTNER, J. The valuation of risk assets and the selection of risky investments in stock portfolios and capital budgets. The review of economics and statistics, v. 47, n. 1, p. 13-37, 1965.

MARMER, M.; HERRMANN, B. L.; DOGRULTAN, E. Premature Scaling. San Francisco, CA: [s.n.], 2012. Disponível em: <http://bit.ly/lorf25b>. Acesso em: 15 set. 2014.

MIRANDA, K. F. et al. Ativos Intangíveis, grau de inovação e o desempenho das empresas brasileiras de grupos setoriais inovativos. Revista Gestão Organizacional, v. 6, n. 1, p. 5-17, 2013.

MYERS, S. C.; MAJLUF, N. S. Corporate financing and investment decisions when firms have information that investors do not have. Journal of Financial Economics, v. 13, n. 2, p. 187-221, jun. 1984.

NASSOUR, A. C. A verdadeira história sobre a descoberta das Américas. Revista Eletrônica de Ciências, v. 19, 2003.

NEELY, A. The performance measurement revolution: why now and what next?

International Journal of Operations \& Production Management, v. 19, n. 2, p. 205-228, 1999.

PANIGRAHI, A. Firms' Life Stage and Capital Structure Decisions. South Asian Journal of Commerce and Management, v. 2, p. 1-54, 2011.

PAUL, S.; WHITTAM, G.; WYPER, J. The pecking order hypothesis: does it apply to startup firms? Journal of Small Business and Enterprise Development, v. 14, n. 1, p. 8-21, 2007.

PEREIRA, L.; GOMES, P. Relação com investidores da pequena empresa ao mercado de capital. 1. ed. Rio de Janeiro: IBRI - CVM, 2014.

PEREZ, M. M. Ativos intengíveis e o desempenho empresarial. R. Cont. Fin., n. 40, p. 7 24, Jan./Abr. 2006.

PINHO, J. A. G. Sociedade da Informação, capitalismo e sociedade civil: reflexões sobre política, Internet e democracia na realidade brasileira. Revista de Administração de Empresas, v. 51, n. 1, p. 98-106, 2011.

PINTO, L. F. G. Capital de risco: uma alternativa de financiamento às pequenas e médias empresas de base tecnológica - o caso do contec. Revista do BNDES, v. 7, n. 1, p. 1-41, 1996.

PORTER, M.; KETELS, C. UK Competitiveness: moving to the next stage. London: Department of Trade and Industry, 2003. DTI Economics Paper No.3. Disponível em: <http://www.bis.gov.uk/files/file14771.pdf>. Acesso em: 23 abr. 2014.

QUANDT, C. O.; FERRARESI, A. A.; BEZERRA, C. A. 10 dimensões da inovatividade e seus impactos no desempenho inovador. In: ENCONTRO DA ANPAD, 37., 2013. Rio de Janeiro. Anais...Rio de Janeiro, 2013. 
QUANDT, C. O.; FERRARESI, A. A.; FREGA, J. R. Gestão de ideias e inovação em grandes empresas do Sul do Brasil. In: ENCONTRO DA ANPAD, 36, 2012. Rio de Janeiro.

Anais...Rio de Janeiro, 2012.

RIES, E. The lean startup. New York: Crown Business, 2011.

ROJO, C. A.; SOUSA, A. F.; TRENTO, F. O reflexo dos ativos intangíveis no valor de mercado de small caps da construção civil que compõem o índice da BM\&F Bovespa. CAP Accounting and Management, v. 6, p. 155-168, 2012.

SAMPIERI, R. H.; COLLADO, C. F.; LUCIO, P. B. Metodologia da pesquisa. São Paulo: McGraw Hill, 2013.

SCHUBERT, P.; HAUSLER, U. E-government meets e-business: a portal site for startup companies in SwitzerlandSystem Sciences. In: ANNUAL HAWAII INTERNATIONAL CONFERENCE ON, 34., Hawaii. Proceedings... Hawaii, 2001.

SHARPE, W. Capital asset prices: A theory of market equilibrium under conditions of risk. The journal of finance, v. 19, n. 3, p. 425-442, 1964.

SILVEIRA, S. M. S. (Coord.). GEM Global Entrepreneurship Monitor:

empreendedorismo no Brasil Relatório Executivo 2016. Curitiba: Curitiba: IBQP, 2017

SPINA, C. A. Investidor anjo guia para empreendedores e investidores. São Paulo: nVersos, 2012.

STINCHCOMBE, A. L. Social structure and organizations. 1. ed. Chicago: Rand McNally, 1965.

SVEIBY, K. E. The intangible assets monitor. Journal of Human Resource Costing \& Accounting, v. 2, n. 1, p. 73-97, 1997.

TEECE, D.; PISANO, G.; SHUEN, A. Dynamic capabilities and strategic management. Strategic Management Journal, 1997.

TIDD, J.; BESSANT, J.; PAVITT, K. Gestão da inovação. 3. ed. Porto Alegre: Bookman, 2008.

VERHEUL, I.; THURIK, R. Start-up capital: “does gender matter?” Small business economics, p. 329-345, 2001. 